\title{
0047. The sound-induced flash illusions reveal visual cortex hyperexcitability in cluster headache
}

\author{
Giuseppe Cosentino ${ }^{*}$, Simona Talamanca, Maria Aprile, Simona Maccora, Roberta Baschi, Laura Pilati, \\ Salvatore Di Marco, Brigida Fierro, Filippo Brighina \\ From Abstracts from the 1st Joint ANIRCEF-SISC Congress \\ Rome, Italy. 29-31 October 2015
}

\section{Objectives}

Pathophysiology of cluster headache $(\mathrm{CH})$ is not wellknown. Although posterior hypothalamus has been suggested to play a pivotal role, evidence exists of a more diffuse involvement of the central nervous system including brainstem and cerebral cortex. In this regard, we recently observed increased motor cortical excitability in episodic $\mathrm{CH}$ patients both outside and inside bout [1]

The sound-induced flash illusions (SIFI) represent an example of multisensory integration, and provide a tool to indirectly explore the excitability state of the visual cortex [2]. SIFI are classified as "fission" and "fusion" illusions. When one visual stimulus (flash) is accompanied by two or more auditory stimuli (beeps), it is often perceived as multiple flashes (fission illusion). Conversely, fusion illusion occurs when subjects perceive less number of flashes when these are presented with only one beep. On such bases, here we used SIFI to explore excitability of visual cortex in $\mathrm{CH}$ patients.

\section{Materials and methods}

SIFI were examined in ten untreated patients with episodic $\mathrm{CH}$ and in twelve age- and sex-matched healthy volunteers. Five out of the ten patients were evaluated both inside (in the interval between two pain attacks) and outside bout. Visual stimuli were accompanied by beeps in different combinations to evaluate both fission illusion (one flash presented with a number of beeps varying between 0 and 4) and fusion illusion (2-4 flashes accompanied by only one beep).

\section{Results}

The fission but not the fusion illusion was significantly reduced in $\mathrm{CH}$ patients with respect to healthy controls. No significant differences were observed between bout and outside bout phases in patients evaluated both in the ictal and interictal state.

\section{Discussion}

The present results provide evidence of increased visual cortical excitability in $\mathrm{CH}$ that is detectable not only during the bout, but also in the pain-free period. This is in agreement with previous findings by our group of increased motor cortex excitability in $\mathrm{CH}$ inside and outside bout.

\section{Conclusions}

These results strengthen the notion that an abnormal cortical excitability state exists in $\mathrm{CH}$. Moreover, findings in $\mathrm{CH}$ patients are very similar to those observed in migraine with aura patients [3], thus supporting the idea that $\mathrm{CH}$ and migraine could share at least some common pathophysiological pathways.

On such bases, we suppose that visual cortex hyperexcitability could play a pathogenic role in $\mathrm{CH}$ as well as in migraine with aura. This suggestion may also be supported by the rather frequent occurrence of aura symptoms in $\mathrm{CH}$ sufferers.

Written informed consent to publication was obtained from the patient(s).

\section{Published: 28 September 2015}

\footnotetext{
References

1. Cosentino G, Brighina F, Brancato S, Valentino F, Indovino S, Fierro B: Transcranial magnetic stimulation reveals cortical hyperexcitability in episodic cluster headache. J Pain 2015, 16(1):53-9.
} 
2. Shams L, Kamitani Y, Shimojo S: Illusions. What you see is what you hear. Nature 2000, 408(6814):788.

3. Brighina F, Bolognini N, Cosentino G, Maccora S, Paladino P, Baschi R, Vallar G, Fierro B: Visual cortex hyperexcitability in migraine in response to sound-induced flash illusions. Neurology 2015, 84(20):2057-61.

doi:10.1186/1129-2377-16-S1-A92

Cite this article as: Cosentino et al:: 0047. The sound-induced flash

illusions reveal visual cortex hyperexcitability in cluster headache. The Journal of Headache and Pain 2015 16(Suppl 1):A92.

\section{Submit your manuscript to a SpringerOpen ${ }^{\mathcal{O}}$ journal and benefit from:}

- Convenient online submission

- Rigorous peer review

- Immediate publication on acceptance

- Open access: articles freely available online

- High visibility within the field

- Retaining the copyright to your article

Submit your next manuscript at $\gg$ springeropen.com 